\title{
Glicemia e concentrações séricas de insulina, triglicérides e cortisol em equinos da raça Mangalarga Marchador após exercício físico ${ }^{1}$
}

\author{
Clarisse S. Coelho ${ }^{2 *}$, Juliana A.N. Gama ${ }^{3}$, Priscila F.R. Lopes ${ }^{4}$ e Vinicius R.C. Souza ${ }^{2}$ \\ ABSTRACT.- Coelho C.S., Gama J.A.N., Lopes P.F.R. \& Souza V.R.C. 2011. [Glycemia and \\ serum concentrations of insuline, triglycerides and cortisol in Mangalarga Marchador \\ horses after physical exercise.] Glicemia e concentrações séricas de insulina, triglicérides \\ e cortisol em equinos da raça Mangalarga Marchador após exercício físico. Pesquisa Veteri- \\ nária Brasileira 31(9):756-760. Programa de Mestrado em Ciência Animal, Centro Universi- \\ tário Vila Velha, Rua Comissário José Dantas de Melo 21, Vila Velha, ES 29102-770, Brazil. E- \\ mail: clarisse.coelho@uvv.br \\ The aim of this study was evaluate the influence of physical exercise of submaximal intensity \\ (marcha gait) on biochemical variables used for the evaluation of energetic metabolism in Man- \\ galarga Marchador horses trained in Espirito Santo, Brazil. Serum and plasma samples were \\ obtained from 15 horses in four different moments: before (T0), 5 minutes (T1), 30 minutes \\ (T2) and 2 hours (T3) after the exercise. Results showed that the imposed exercise did not \\ influence plasmatic glucose, with mean values of $117.1 \pm 5.8 \mathrm{~g} / \mathrm{dL}, 122.6 \pm 59.6 \mathrm{mg} / \mathrm{dL}$, \\ $124.8 \pm 48.6 \mathrm{mg} / \mathrm{dL}$ and $112.9 \pm 49.1 \mathrm{mg} / \mathrm{dL}$, and serum insuline, with median values of $6.50 \mu \mathrm{UI} /$ \\ $\mathrm{mL}, 2.00 \mu \mathrm{UI} / \mathrm{mL}, 5.85 \mu \mathrm{UI} / \mathrm{mL}$ and $11.60 \mu \mathrm{UI} / \mathrm{mL}$, respectively on the moments $\mathrm{T} 0, \mathrm{~T} 1, \mathrm{~T} 2$ and \\ T3. Differently, it was possible to observe a positive influence of the exercise over serum \\ triglycerides, with mean values of $25.4 \pm 14.9 \mathrm{mg} / \mathrm{dL}, 42.3 \pm 17.8 \mathrm{mg} / \mathrm{dL}, 31.4 \pm 17.7 \mathrm{mg} / \mathrm{dL}$ and \\ $25.1 \pm 15.1 \mathrm{mg} / \mathrm{dL}$, and serum cortisol, with mean values of $7.46 \pm 4.37 \mathrm{mg} / \mathrm{dL}, 12.45 \pm 3.08 \mathrm{mg} /$ \\ $\mathrm{dL}, 11.40 \pm 2.52 \mathrm{mg} / \mathrm{dL}$ and $6.89 \pm 1.78 \mathrm{mg} / \mathrm{dL}$, respectively on the moments $\mathrm{T} 0, \mathrm{~T} 1, \mathrm{~T} 2$ and $\mathrm{T} 3$. It \\ was possible to conclude that the marcha gait leaded to an elevation of serum triglycerides and \\ cortisol levels. Also, as the values found were within reference levels, it was possible to conclude \\ that the horses were used to this physical activity imposed on the occasion.
}

INDEX TERMS: Glycemia, glucose, cortisol, insuline, marcha gait, exercise, horses.

RESUMO.- 0 presente estudo teve por objetivo avaliar a influência do exercício físico de intensidade submáxima (provas de marcha) sobre as variáveis bioquímicas sanguíneas usadas na avaliação do metabolismo energético em equinos da raça Mangalarga Marchador criados no Estado do Espírito Santo. Para tal foram obtidas amostras de soro e plasma de 15 equinos, da raça Mangalarga Marchador, em quatro momentos assim definidos: antes (T0) e com 5 minutos (T1), 30 minutos (T2) e 2 horas (T3) após o término do exercício. A análise dos resultados demonstrou a não influência do exercício físico imposto sobre a glicose plasmática, com valores

\footnotetext{
${ }^{1}$ Recebido em 5 de abril de 2011.

Aceito para publicação em 25 de junho de 2011.

${ }^{2}$ Programa de Mestrado em Ciência Animal, Centro Universitário Vila Velha (UVV), Rua Comissário José Dantas de Melo 21, Vila Velha, ES 29102-770, Brasil. *Autor para correspondência: clarisse.coelho@uvv.br

${ }^{3}$ Curso de Medicina Veterinária, UVV, Vila Velha, ES.

${ }^{4}$ Programa de Residência em Medicina Veterinária, UVV, Vila Velha, ES.
}

médios de $117,1 \pm 35,8 \mathrm{mg} / \mathrm{dL}, 122,6 \pm 59,6 \mathrm{mg} / \mathrm{dL}, 124,8 \pm$ $48,6 \mathrm{mg} / \mathrm{dL}$ e $112,9 \pm 49,1 \mathrm{mg} / \mathrm{dL}$, e sobre a insulina sérica, com valores de mediana de $6,50 \mu \mathrm{UI} / \mathrm{mL}, 2,00 \mu \mathrm{UI} / \mathrm{mL}$, $5,85 \mu \mathrm{UI} / \mathrm{mL}$ e $11,60 \mu \mathrm{UI} / \mathrm{mL}$, respectivamente, nos tempos T0, T1, T2 e T3. De forma oposta, foi possível observar uma influência significativa sobre triglicérides séricos, com valores médios de $25,4 \pm 14,9 \mathrm{mg} / \mathrm{dL}, 42,3 \pm 17,8 \mathrm{mg} / \mathrm{dL}$, $31,4 \pm 17,7 \mathrm{mg} / \mathrm{dL}$ e $25,1 \pm 15,1 \mathrm{mg} / \mathrm{dL}$, e sobre o cortisol sérico, com valores médios de $7,46 \pm 4,37 \mathrm{mg} / \mathrm{dL}, 12,45 \pm 3,08 \mathrm{mg} / \mathrm{dL}$, $11,40 \pm 2,52 \mathrm{mg} / \mathrm{dL}$ e $6,89 \pm 1,78 \mathrm{mg} / \mathrm{dL}$, respectivamente nos tempos T0, T1, T2 e T3. A interpretação destes resultados permitiu concluir que a marcha elevou as concentrações séricas de triglicérides e cortisol. Também foi possível destacar que, por tais valores encontrarem-se dentro de intervalos fisiológicos, os equinos usados estavam aptos ao nível de exercício físico imposto na ocasião.

TERMOS DE INDEXAÇÃO: Glicemia, glicose, cortisol, insulina, marcha, exercício, equinos. 


\section{INTRODUÇÃO}

A raça Mangalarga Marchador (ou "Mangalarga Mineiro") é a mais numerosa do país. Tipicamente brasileira, surgiu há cerca de 200 anos no sul de Minas Gerais, através do cruzamento de cavalos da raça Alter (Coudelaria de Alter do Chão, Portugal) com outros cavalos selecionados pelos criadores daquela região mineira (ABCCMM 2011). Poucas pesquisas são realizadas com esta raça, cujo andamento característico é a marcha, um teste exaustivo sem similar em todo o mundo onde o animal realiza um exercício de longa duração, com grande gasto energético, num percurso em círculo, sem repouso e em velocidade constante (Rezende 2006).

É sabido que o exercício físico realizado durante treinamentos ou competições gera em humanos e animais variações em diversos parâmetros fisiológicos (Kienzle et al. 2006), com a participação importante do sistema endócrino (Mircean et al. 2007). Hyyppä (2005) relatou que o exercício físico desencadeia a liberação de diversos hormônios, principalmente as catecolaminas, cuja principal função é a mobilização e utilização do substrato energético, através da quebra de glicogênio e lipólise, com consequente liberação de ácidos graxos livres. A liberação das catecolaminas no exercício ocorre tanto em equinos treinados quanto em não treinados (Baragli et al. 2011).

Outro hormônio liberado com a atividade física é o cortisol em resposta a elevação de ACTH, com pico circulatório cinco a 30 minutos após o término do exercício (Gordon et al. 2007). Segundo Hyyppä (2005), sua principal função é prover a biodisponibilidade dos precursores energéticos necessários para manter os esforços musculares através de diversas vias de ação, dentre as quais degradação de proteínas teciduais para liberação de aminoácidos usados na gliconeogênese hepática, mobilização de ácidos graxos livres do tecido adiposo e redução da taxa de utilização celular de glicose. No repouso, Marc et al. (2000) citaram intervalo de valores entre 1,47 e $6,73 \mathrm{mg} / \mathrm{dL}$ e Williams et al. (2002) descreveram valores entre 4,5 e 7,5mg/dL. Trabalho mais recente de Dugat et al. (2010) cita valores oscilando entre 2,9 e $6,6 \mathrm{mg} / \mathrm{dL}$.

Sendo assim, o aumento do cortisol sérico durante provas equestres é esperado (Kraemer et al. 2003, Mircean et al. 2007). Porém, esta resposta varia conforme a intensidade e duração do exercício, nível de condicionamento atlético, estado nutricional e até mesmo ritmo circadiano, sendo que seu aumento já foi correlacionado tanto com exercício de alta intensidade quanto com exercício físico constante e moderado por tempo prolongado (McArdle et al. 1998, Islas et al. 2007). Trabalho recente de Ferraz et al. (2010) citaram que o aumento de cortisol no pós-exercício estaria mais relacionada com a duração do mesmo, podendo os valores atingir o dobro do registrado no repouso.

Segundo diversos autores (Marc et al. 2000, Islas et al. 2007, Mircean et al. 2007, Ferraz et al. 2010), a mensuração de cortisol sérico poderia ser usada como índice de avaliação de treinamento, pois sua liberação é menor em indivíduos treinados quando comparados aos não treinados quando os mesmos são submetidos ao mesmo tipo de exercício durante o mesmo tempo. Porém, os valores pós-prova são sempre superiores aos encontrados no repouso (Islas et al. 2007).

Como consequência das catecolaminas circulantes frente ao exercício físico, há a redução na liberação de insulina e o aumento de glucagon circulante (McKeever 2002, Hyyppä 2005), que somados a ação do cortisol, promovem um efeito hiperglicemiante. 0 aumento da glicemia no exercício foi descrito em trabalhos de Gordon et al. (2007) e Ferraz et al. (2010), trabalhando com equinos em diferentes intensidades de atividade física. Martins et al. (2005) citaram valores de glicemia em cavalos da raça Árabe no repouso de $86,9 \mathrm{mg} /$ dL atingindo 116,3 mg/dL 30 minutos após o mesmo. Adicionalmente, Freestone et al. (1991) e Orozco et al. (2007) comprovaram, além do aumento da glicemia, uma redução concomitante dos valores séricos de insulina. Dugat et al. (2010) citaram valores de referência de insulina para equinos no repouso entre 4,9 e $45,5 \mu \mathrm{UI} / \mathrm{mL}$.

Em consequência do equilíbrio energético negativo provocado por ação de catecolaminas e cortisol, semelhante ao provocado pelo jejum alimentar, há aumento da lipólise e do catabolismo de proteínas corporais (Durham 2006). Segundo Dugat et al. (2010), os valores séricos de triglicérides no repouso atingem $33,82 \mathrm{mg} / \mathrm{dL}$ e no jejum chegam a $112,74 \mathrm{mg} / \mathrm{dL}$. Apesar dos poucos estudos envolvendo o metabolismo lipídico frente ao exercício, acredita-se que a resposta observada seja semelhante. Orozco et al. (2007) observaram aumento gradativo nos valores de triglicérides séricos com o aumento do esforço físico dos equinos de enduro avaliados em seu experimento (de $34,9 \mathrm{mg} / \mathrm{dL}$ no momento antes a 58,5mg/dL no momento de desaceleração). Segundo os mesmos autores, isto pode ser explicado devido ao maior requerimento de energia frente ao exercício e provavelmente porque se inicia um processo oxidativo de triglicérides no músculo esquelético que atuam como precursores dos ácidos graxos livres. Durante a recuperação do exercício, as concentrações plasmáticas de triglicérides caem consideravelmente, conforme a de insulina aumenta em consequência do retorno alimentar (Hyyppä 2005).

A compreensão de tais mecanismos fisiológicos e sua caracterização são de enorme importância na avaliação da performance de equinos atletas (Marques 2002). Sendo assim, o objetivo do presente trabalho foi avaliar a influência do exercício físico de intensidade submáxima (provas de marcha) sobre as variáveis bioquímicas sanguíneas rotineiramente usadas na avaliação do metabolismo energético (cortisol, insulina e triglicérides séricos e glicose plasmática) em equinos da raça Mangalarga Marchador criados no Estado do Espírito Santo.

\section{MATERIAL E MÉTODOS}

O presente projeto de pesquisa teve aprovação do Comitê de Bioética Animal da UVV, sendo registrado sob o número 72/2009. Foram utilizados 15 equinos da raça Mangalarga Marchador, sendo nove fêmeas e seis machos, pesando em média $399 \pm 34 \mathrm{~kg}$, com idade variando entre três e dez anos (média de 4,6 $\pm 1,9$ anos de idade), considerados clinicamente hígidos, mediante exames clínicos e laboratoriais. Estes animais pertencem a haras localizados na região da grande Vitória, estado do Espírito Santo. A temperatura média local é de $24^{\circ} \mathrm{C}$ e a umidade relativa do ar de $80 \%$.Todos os animais usados são submetidos ao mesmo tipo de manejo alimentar e sanitário.

A alimentação dos animais foi baseada nos relatos de Ralston (1988), sendo fornecido feno de coast-cross (Cynodon dactylon $\mathrm{x}$ Cynodon nlemfluensis) ad libitum e ração comercial, com $12 \%$ de proteína bruta, a $1 \%$ do peso corporal, divididos em três vezes ao dia. A água e sal mineral foram fornecidos ad libitum. 
Todos os equinos selecionados encontravam-se no mesmo estágio de treinamento e executavam tal atividade há pelo menos dois anos. 0 treinamento semanal consistia de exercício com o animal sendo puxado por um período de 25 a 30 minutos até 2 a 3 horas, duas vezes na semana, alternando nos demais três dias com exercícios montados, em marcha, por 15 a 30 minutos. Aos finais de semana os animais descansavam.

Na presente pesquisa, os animais executaram marcha cadenciada, sendo 20 minutos em sentido horário e 20 minutos em sentido anti-horário, em velocidade média de 9 a $12 \mathrm{~km} / \mathrm{h}$, totalizando 40 minutos.

Foram quatro momentos de avaliação de cada um dos equinos, sendo assim caracterizadas: antes - T0 (obtida antes do exercício físico, com o animal em repouso), T1 (obtida num período máximo de cinco minutos após a realização da atividade física), T2 (obtida 30 minutos após a realização da atividade física) e T3 (obtida 2 horas após a realização da atividade física). No dia do esforço físico foram registradas as condições de tempo (temperatura e umidade), Todas as atividades foram realizadas no período da manhã (entre 6h:00 e 11h:00), quando também foram registradas as características da pista.

As amostras de sangue foram obtidas, após antissepsia local, por meio de venopunção da jugular com agulhas descartáveis $(25 \mathrm{~mm} \times$ $0,8 \mathrm{~mm}$ ), utilizando-se sistema de pressão negativa ${ }^{5}$, em tubos de vidro contendo anticoagulante EDTA-fluoreto de sódio com capacidade de $2 \mathrm{ml}$, para avaliação plasmática de glicose, e em tubos de vidro siliconizados sem anticoagulante com capacidade de $9 \mathrm{ml}$, para as determinações séricas de cortisol, insulina e triglicérides. Todas as 60 amostras foram transportadas sob refrigeração ao Laboratório Clínico Veterinário do Centro Universitário Vila Velha (UVV), onde foram imediatamente centrifugadas (3500 rpm) durante $10 \mathrm{minu}-$ tos (Centrífuga modelo TDL80-2B, Marca Centribio) para separação de soro/plasma, que imediatamente foram congelados.

Para determinação de cortisol sérico foi utilizada a técnica de radioimunoensaio em fase sólida usando kit comercial (Siemens Coat-a-Count), conforme especificações do fabricante. Já para a determinação da insulina sérica, foi utilizada a técnica de quimioluminescência, usando kit comercial (Siemens Immulite) conforme especificações do fabricante. Todos os testes foram realizados em duplicata e previamente validados para uso em equinos, de acordo com metodologia descrita por Freestone et al. (1991). Tais determinações foram realizadas no Hérmes Pardini Laboratórios (Belo Horizonte, MG).

A glicose plasmática foi determinada através de metodologia enzimática (Schmid \& Forstner 1986), utilizando kit comercial (Bioclin Glicose K054), em comprimento de onda de $510 \mathrm{~nm}$, e determinação sérica de triglicérides foi feita através de método enzimático colorimétrico (Bergmeyer 1974), usando kit comercial (Bioclin Triglicérides Liquido Estável K055), em comprimento de onda de $540 \mathrm{~nm}$, ambos em aparelho analisador semi-automático (Bioplus - BIO200).

A análise dos resultados foi realizada utilizando-se o programa estatístico computadorizado GraphPad InStat (versão 3.0). Devido à distribuição gaussiana dos dados registrados para cortisol e triglicérides séricos e glicose plasmática, os mesmos foram avaliados através de testes paramétricos (análise de variância - ANOVA) seguido da comparação entre médias (teste de Tukey) com nível de significância de 5\%. Já a análise dos resultados referentes a insulina sérica foi feita usando testes não paramétricos devido a distribuição não gaussiana dos dados. Sendo assim, o teste usado em sua avaliação foi Kruskal-Wallis com nível de significância de 5\%. Em todas as análises levou-se em consideração a influência do exercício físico sobre as concentrações das variáveis estudadas.

\footnotetext{
${ }^{5}$ Vacutainer.
}

\section{RESULTADOS}

Nos exames clínicos e laboratoriais realizados para seleção dos equinos usados na presente pesquisa, os valores médios registrados foram: frequência cardíaca de 45 bpm, frequência respiratória de $20 \mathrm{mpm}$, motilidade intestinal presente à auscultação, mucosas róseas e temperatura retal de $37,5^{\circ} \mathrm{C}$.

Os equinos usados foram exercitados em três dias, sendo avaliados cinco animais em cada dia. A pista de grama encontrava-se seca. As características climáticas locais são típicas de climas tropicais (quente e úmido).

No Quadro 1 estão apresentados os valores médios e desvios-padrão para os valores plasmáticos de glicose e valores séricos de cortisol e triglicérides séricos, além dos valores de $p$ obtidos na análise de variância (ANOVA). Já no Quadro 2 estão apresentados mediana e os valores máximos e mínimos de insulina sérica e valor de $p$ obtido no teste de KruskalWallis. Na avaliação dos resultados obtidos, foi possível observar que o exercício físico imposto influenciou de forma altamente significativa $(\mathrm{p}<0,0001)$ as concentrações séricas de cortisol, bem como de triglicérides $(\mathrm{p}=0,0204)$.

Não houve influência do tipo de exercício imposto sobre a glicose plasmática $(p=0,9119)$ e insulina sérica $(p=0,1354)$ ao longo do período experimental.

\section{DISCUSSÃO}

Muitos estudos avaliaram os efeitos de exercícios, de diferentes intensidades e duração, sobre diversos constituintes sanguíneos, visando sua melhor compreensão frente ao desafio imposto e, com isto, determinar se tais parâmetros poderão ou não ser usados como índices de condicionamento atlético em equinos. Adicionalmente, esta correta interpretação depende também do estabelecimento de valores de referência nacionais, seja no repouso ou após atividades atléticas, para as diferentes raças usadas nos esportes hípicos. Entretanto, ainda são escassas as pesquisas realizadas no Brasil, tanto aquelas envolvendo o sistema endócrino em equinos atletas treinados em condições tropicais, bem como a caracterização das alterações observadas em equinos da raça Mangalarga Marchador.

Os valores de hemograma encontravam-se dentro da normalidade para a espécie conforme Robinson (2003).

Os valores de cortisol sérico registrados na presente pesquisa em todos os momentos de avaliação são superiores aos descritos por Marc et al. (2000) e Dugat et al. (2010), sendo semelhantes aos de Williams et al. (2000) somente nos momentos antes e com duas horas após o término do exercício físico. Corroborando com o trabalho de Gordon et al. (2007) e Islas et al. (2007), os maiores valores na presente pesquisa foram registrados entre 5 e 30 minutos após o término da atividade física, justificando tal fato como resposta aguda frente ao estresse.

Orozco et al. (2007), em trabalho nacional usando equinos da raça Árabe exercitados em esteira ergométrica, registraram aumento significativo com valores de 7,24mg/dL no momento antes e $8,19 \mathrm{mg} / \mathrm{dL}$ no momento da suspensão do exercício, justificando tal achado pela necessidade da liberação de precursores energéticos (glicose e ácidos graxos livres) essenciais para a execução da atividade física (Mircean et al. 2007). Este aumento também foi registrado na presente pes- 
Quadro 1. Valores médios e desvios-padrão da concentração de glicose plasmática e de cortisol e triglicérides séricos nos equinos da raça Mangalarga Marchador, em uma sessão de exercício físico, nos momentos T0, T1, T2 e T3

\begin{tabular}{lccccc}
\hline & T0 & T1 & T2 & T3 & $p$ \\
\hline Glicose(mg/dL) & $117,1 \pm 35,8^{\mathrm{a}^{*}}$ & $122,6 \pm 59,6^{\mathrm{a}}$ & $124,8 \pm 48,6^{\mathrm{a}}$ & $112,9 \pm 49,1^{\mathrm{a}}$ & 0,9119 \\
Cortisol(mg/dL) & $7,46 \pm 4,37^{\mathrm{a}}$ & $12,45 \pm 3,08^{\mathrm{b}}$ & $11,40 \pm 2,52^{\mathrm{bc}}$ & $6,89 \pm 1,78^{\mathrm{a}}$ & $<0,0001$ \\
Triglicérides(mg/dL) & $25,4 \pm 14,9^{\mathrm{a}}$ & $42,3 \pm 17,8^{\mathrm{b}}$ & $31,4 \pm 17,7^{\text {ab }}$ & $25,1 \pm 15,1^{\mathrm{a}}$ & 0,0204 \\
\hline
\end{tabular}

* Letras minúsculas diferentes na mesma linha denotam diferença estatística significativa entre as medias $(\mathrm{p}<0,05)$ obtido pelo teste ANOVA. T0 (obtida antes da atividade física), T1 (obtida num período de até no máximo cinco minutos após o término da atividade física), T2 (obtida 30 minutos após o término da atividade física) e T3 (obtida 2 horas após o término da atividade física).

Quadro 2. Mediana e valores máximos e mínimos da insulina sérica $(\mu \mathrm{UI} / \mathrm{mL})$ nos equinos da raça Mangalarga Marchador , em uma sessão de exercício físico,nos momentos T0, T1, T2 e T3

\begin{tabular}{lccccc}
\hline & T0 & T1 & T2 & T3 & $p$ \\
\hline Mediana & $6,50^{\mathrm{a}^{*}}$ & $2,00^{\mathrm{a}}$ & $5,85^{\mathrm{a}}$ & $11,60^{\mathrm{a}}$ & 0,1354 \\
Valor mínimo & 2,00 & 2,00 & 2,00 & 2,00 & \\
Valor máximo & 71,20 & 42,10 & 191,00 & 73,20 &
\end{tabular}

* Letras minúsculas diferentes na mesma linha denotam diferença estatística significativa entre as medias $(\mathrm{p}<0,05)$ obtido pelo teste KruskalWallis. T0 (obtida antes da atividade física), T1 (obtida num período de até no máximo cinco minutos após o término da atividade física), T2 (obtida 30 minutos após o término da atividade física) e T3 (obtida 2 horas após o término da atividade física).

quisa e foi semelhante aos achados de Islas et al. (2007) e Ferraz et al. (2010), porém os valores após o exercício físico foram superiores em comparação ao registrado por Orozco et al. (2007). Isto se deve provavelmente ao fato de que, apesar da duração semelhante de atividade física imposta em ambas as pesquisas, a marcha, caracterizada pela velocidade constante média de aproximadamente $10 \mathrm{~km} / \mathrm{h}$, representa um exercício de intensidade superior do que a executada pelos animais na pesquisa de Orozco et al. (2007), além do fato da pesquisa a campo gerar mais estresse em função de variações climáticas e condições de pista.

Marc et al. (2010) registraram que o treinamento físico tende a reduzir a magnitude de elevação do cortisol após provas e/ou exercícios. Desta forma, segundo Ferraz et al. (2010), sua mensuração poderia ser usada como ferramenta na avaliação do treinamento imposto. Para tal são necessárias ao menos duas avaliações físicas entre um período determinado de treino para verificar se este foi eficiente. Apesar disto não ter sido feito na presente pesquisa, os resultados demonstraram a importância do uso desta ferramenta na avaliação do condicionamento atlético frente a uma única sessão de exercícios, com amostras obtidas antes e sequencialmente após o término da mesma.

Reforçando a afirmação anterior, com duas horas após a finalização do esforço físico, foi possível observar o retorno aos valores basais do cortisol sérico registrados antes do mesmo. Segundo Mircean et al. (2007), exercícios excessivos ou treinamento insuficiente geram, em teoria, aumento persistente (por mais de duas horas) do cortisol, fato não registrado nos equinos usados nesta pesquisa, sugerindo o bom condicionamento atlético destes animais frente ao exercício imposto.

Por se tratar de um estudo envolvendo avaliação hormonal e sabendo do ritmo circadiano da liberação de cortisol, é ex- tremamente importante padronizar a hora na qual o exercício físico será executado. Para evitar grandes oscilações dos valores estudados e ter resultados mais fidedignos, a presente pesquisa foi realizada no período da manhã, que coincide com o pico de liberação de cortisol, segundo Islas et al. (2007).

0 aumento esperado do cortisol sérico frente a um exercício físico, conforme também foi constatado neste estudo, desencadeia uma cascata de eventos endócrinos, tendo em grande parte a participação conjunta das catecolaminas (Baragli et al. 2011). Estas alterações fisiológicas incluem a redução na ação da insulina, hiperglicemia e aumento de triglicérides séricos, visando a produção eficiente de energia para manutenção dos esforços musculares (Mircean et al. 2007).

0 efeito hiperglicemiante, transitório visto a normalização dos valores após o término do exercício, foi constatado por Martins et al. (2005), Gordon et al. (2007) e Ferraz et al. (2010). Entretanto, na presente pesquisa, apesar do pico de glicemia obtido com 30 minutos após o término do exercício $(124,8 \pm 48,6 \mathrm{mg} / \mathrm{dL})$, não houve diferença significativa para o momento T0 $(117,1 \pm 35,8 \mathrm{mg} / \mathrm{dL})$ e para o momento T3 $(112,9 \pm 49,1 \mathrm{mg} / \mathrm{dL})$, com os resultados apenas sugerindo uma hiperglicemia gerada pela execução da atividade física. Mesmo assim, foi caracterizada a presença da hiperglicemia porque os valores estavam superiores ao intervalo de referência descrito por Robinson (2003) para a espécie equina (75,0-115,0mg/dL). Tal hiperglicemia é esperada como consequência da ação do cortisol.

Outro fator que contribui para o efeito hiperglicemiante gerado no exercício é o bloqueio na liberação da insulina provocada pela ação de catecolaminas e cortisol. Nos equinos da raça Mangalarga Marchador usados na presente pesquisa, os valores medianos registrados oscilaram entre 2,00 mUI/ $\mathrm{ml}$, mais baixo registrado no momento $\mathrm{T} 1$, a $11,60 \mathrm{mUI} / \mathrm{ml}$, mais elevado registrado no momento T3. Segundo Dugat et al. (2010), os valores registrados encontram-se dentro do intervalo de referência para equinos.

Apesar da redução observada entre os momentos T0 e $\mathrm{T} 1$, sugerindo o bloqueio na liberação da insulina, conforme descrito por Freestone et al. (1991), estes registros não apresentaram diferença significativa. Sendo assim, os resultados demonstraram a não influência do exercício físico sobre esta variável sanguínea, semelhante ao relatado por Hyyppä (2005) e Gordon et al. (2007). Tais autores reforçam uma maior influência alimentar, com as elevações séricas deste hormônio ocorrendo quando os equinos voltam a receber alimentos. $\mathrm{O}$ pico registrado na presente pesquisa ocorreu no momento $\mathrm{T} 3$, quando os equinos já tinham retornado às 
suas baias e alimentação a base de concentrado havia sido fornecida. Concentrações elevadas de insulina durante o esforço físico são consideradas prejudiciais (McKeever 2002). Segundo este mesmo autor, uma prova disto seria o fornecimento de uma refeição rica em carboidratos próximo a uma atividade atlética, que normalmente provoca aumento de insulina gerando queda da glicose plasmática e, com isto, queda na disponibilidade da mesma como fonte energética.

Na presente pesquisa foi observado aumento significativo de triglicérides séricos no momento T1, com subsequente retorno aos valores basais no momento T3. Os valores registrados encontram-se dentro da faixa de normalidade para a espécie equina descrita por Robinson (2003), que cita intervalo de 5,3 a 54,0mg/dL. Este aumento significativo também foi registrado por Orozco et al. (2007), porém estes autores descreveram valores ligeiramente superiores $(34,0$ no momento antes e $58,5 \mathrm{mg} / \mathrm{dL}$ no momento após com os equinos em desaceleração) aos citados na presente pesquisa. Este aumento de triglicérides séricos é esperado em consequência do bloqueio na ação da insulina e do efeito hiperglicemiante gerado pelas catecolaminas e cortisol circulantes frente ao esforço físico. Com isto, ocorre um balanço energético negativo, semelhante ao que ocorre quando um equino é submetido a jejum alimentar, havendo lipólise e mobilização de outras fontes energéticas (Durham 2006, Dugat et al. 2010).

Hyyppä (2005) afirmou que a recuperação das concentrações séricas de triglicérides é lenta no pós-exercício. Segundo o autor, com uma hora após o término do exercício, há o aumento na liberação de insulina, que por sua vez inibe a lipólise num momento em que as concentrações séricas de lipídeos já estariam baixas em função de seu uso como fonte energética. Isto não foi observado na presente pesquisa com o retorno aos valores basais sendo registrados no momento $\mathrm{T} 2$, duas horas após o término da atividade física.

\section{CONCLUSÕES}

Os resultados da presente pesquisa nos permitiram concluir que o exercício físico imposto através da prova de marcha não influenciou os valores de glicose plasmática e insulina sérica, porém gerou um aumento significativo nos valores séricos de cortisol e triglicérides.

Foi também possível concluir que os equinos usados na referida sessão de exercício encontravam-se fisicamente condicionados ao tipo de exercício imposto, visto que os valores registrados estavam dentro de limites fisiológicos pós-exercício, e os animais não demonstraram sinais clínicos de fadiga.

Agradecimentos.- À Funadesp (Fundação Nacional de Desenvolvimento do Ensino Superior Particular), pela concessão da bolsa de pesquisa. Ao Haras Água Limpa de Mangalarga Marchador.

\section{REFERÊNCIAS}

ABCCMM 2011. Provas Técnicas. Disponível em <http//http://www. abccmm.org.br> Acesso em 9 fev. 2011.

Baragli P.B., Sgorbini M., Casini L., Ducci M. \& Sighieri C. 2011. Early evidence of the anticipatory responde of plasma catecholamine in equine exercise. J. Eq. Vet. Sci. 31:85-88.
Bergmeyer H.U. 1974. Methods of Enzymatic Analysis. Academic Press, New York. 1064p.

Dugat S.L., Taylor T.S., Matthews N.S. \& Gold J.R. 2011. Values for triglycerides, insulin, cortisol and ACTH in a herd of normal donkeys. J. Eq. Vet. Sci. 30(3):141-144.

Durham A.E. 2006. Clinical application of parenteral nutrition in the treatment of five ponies and one donkey with hyperlipaemia. Vet. Rec. 158:159-164.

Ferraz G.C., Teixeira-Neto A.R., Pereira M.C., Linardi R.L., Lacerda-Neto J.C. \& Queiroz-Neto A. 2010. Influência do treinamento aeróbico sobre o cortisol e glicose plasmaticos em equinos. Arq. Bras. Med. Vet. Zootecn. 62(1):23-29.

Freestone J.F., Wolfsheimer K.J., Kamerling S.G., Church G., Hamra J. \& Bagwell C. 1991. Exercise induced hormonal and metabolic changes in Thoroughbred horses: Effects of conditioning and acepromazine. Equine Vet. J. 23(3):219-223.

Gordon M.E., McKeever K.H., Betros C.L. \& Manso Filho H.C. 2007. Exerciseinduced alterations in plasma concentrations of ghrelin, adiponectin, leptin, glucose, insulin and cortisol in horses. Vet. Journal 173:532-540.

Hyyppä S. 2005. Endocrinal responses in exercising horses. Livestock Product. Sci. 92:113-121.

Islas A., Merino V., Mora G., Quezada M., Kraushaar R. \& Araya H. 2007. Evaluacion de estres en equinos en entrenamiento para participar en prueba de resistencia. Agro Ciênc. 23(2):73-78.

Kienzle E., Freismuth A. \& Reusch A. 2006. Double blind placebo controlled vitamin E ou selenium supplementation of Sport horses with unspecified muscle problems. J. Nutrition 136(7):2045-2047.

Kraemer R.R., Aboudehen K.S., Carruth A.K., Durand R.T., Acevedo E.O., Hebert E.P., Johnson L.G. \& Castracane V.D. 2003. Adiponectin responses to continuous and progressively intense intermittent exercise. Med. Sci. Sport Exerc. 35(8):1320-1325.

Marc M., Parvizi N., Ellendorff F., Kallweit E. \& Elsaesser F. 2000. Plasma cortisol and ACTH concentrations in the warmblood horse in response to a standardized treadmill exercise test as physiological markers for evaluation of training status. J. Anim. Sci. 78:1936-1946.

Marques M.S. 2002. Influência do exercício físico sobre os níveis de lactato plasmático e cortisol sérico em cavalos de corrida. Dissertação em Mestrado, Faculdade de Medicina Veterinária e Zootecnia, USP, São Paulo. 70p.

Martins C.B., Orozco C.A.G., D’Angelis F.H.F., Freitas E.V.V., Christovão F.G., Queiroz Neto A. \& Lacerda Neto J.C. 2005. Determinação de variáveis bioquímicas em equinos antes e após a participação em provas de enduro. Revta Bras. Ciênc. Vet. 12(1/3):62-65.

McArdle W.D., Katch F.I. \& Katch V.L. 1998. Fisiologia do Exercício. Guanabara-Koogan, Rio de Janeiro, p.117-133, 339-367.

McKeever K.H. 2002. The endocrine system and the challenge of exercise. Vet. Clin. North Am., Equine Pract. 18(2):321-353.

Mircean M., Giurgiu G., Mircean V. \& Zinveliu E. 2007 Serum cortisol variation of sport horses in relation with the level of training and effort intensity. Bulletin USAMV-CN 64:488-492.

Orozco A.A.G., Martins C.B., Gomide L.M., Queiroz-Neto A. \& Lacerda-Neto J.C. 2007. Alteraciones metabólicas durante entrenamiento en equinos de la Raza Pura Sangre Árabe. Revta Med. Vet. 13:77-82.

Ralston S.L. 1988. Equine Clinical Nutrition: Specific problems and solutions. Comp. Cont. Educ. 10(3):356-363.

Rezende A.S.C. 2006. Aditivos ou suplementos? Mangalarga Marchador. Revta Oficial ABCCMM 18(59):44-48.

Robinson E.N. 2003. Current Therapy in Equine Medicine. $5^{\text {th }}$ ed. W.B. Saunders, Philadelphia. 960p.

Schmid M. \& Fostner L.A. 1986. Laboratory Testing in Veterinary Medicine Diagnosis in the Clinical Monitoring. Boehringer, Mannheim. 253p.

Williams R.J., Marlin D.J., Smith N., Harris R.C., Haresign W. \& Davies Morel M.C. 2002. Effects of cool and hot humid environment conditions on neuroendocrine responses of horses to treadmill exercise. Vet. Journal 164:54-63. 